\title{
Reação de acessos de Cucurbita sp. ao Zucchini yellow mosaic virus (ZYMV)
}

\author{
Maria da C.C.L. Moura ${ }^{1}$; Francisco Murilo Zerbini²; Derly José H. da Silva²; Manoel Abílio de Queiroz ${ }^{3}$ \\ ${ }^{1}$ UEMA/FAPEMA,Campus Paulo VI, C. Postal 3004, 65055-098 SãoLuís-MA; ${ }^{2}$ UFV, 36571-000Viçosa-MG; ${ }^{3}$ UNEB, Juazeiro-BA; E- \\ mail:avmmoura51@ hotmail.com
}

\section{RESUMO}

Cucurbita moschata pode ser infectada por várias espécies de vírus, dentre os quais se destacam os pertencentes à família Potyviridae. No presente estudo avaliou-se os acessos de abóbora pertencentes às coleções dos Banco de Germoplasma de Hortaliças da UFV e Banco Ativo de Germoplasma de Cucurbitáceas da Embrapa Semi-Árido, visando identificar fontes de resistência ao potyvírus Zucchini yellow mosaic virus (ZYMV). Dos 100 acessos de abóbora avaliados, 61 pertencem ao BAG-Embrapa Semi-Árido, 37 ao BGH-UFV e dois à empresa de sementes Sakata Seed Sudamerica. Quatro plantas de cada acesso foram inoculadas com o ZYMV, em telado, na fase cotiledonar, antes do aparecimento da primeira folha verdadeira, e reinoculadas dois dias depois. As plantas que persistiram sem sintomas, por até 30 dias após a primeira inoculação, foram avaliadas para a presença do ZYMV por ELISA indireto. Dentre os acessos avaliados, três (BGH-1934, BGH-1937 e BGH-1943) foram imunes ao ZYMV quando inoculados na época mais quente do ano. Os acessos suscetíveis apresentaram sintomas 10 a 15 dias após a primeira inoculação, nas duas épocas estudadas (janeiro e julho). Os genótipos resistentes permaneceram sem sintomas até o final da avaliação e a concentração viral foi baixa. Os acessos BGH-1934, BGH-1937 e BGH-1943 poderão ser utilizados em programas de melhoramento que visem incorporar resistência ao ZYMV em cultivares comerciais.

\begin{abstract}
Identification of pumpkin populations as resistance sources against the Zucchini yellow mosaic virus (ZYMV)

Cucurbita moschata is subject to infection by several viruses, especially from the family Potyviridae. The pumpkin accessions of the Vegetable Germplasm Bank Collection of the Universidade Federal de Viçosa and the Cucurbitaceae Germplasm Active Bank from the Embrapa SemiArido was evaluated to identify sources of resistance to the virus ZYMV. A total of 100 pumpkin accessions was evaluated, 61 from Embrapa Semi-Árido, 37 from UFV, and two from the seed company Sakata Seed Sudamerica. Four plants of each accession were inoculated with ZYMV during the cotyledonar phase before emergence of the first true leaves. Plants were reinoculated two days later. Plants without symptoms after 30 days of the first inoculation were evaluated for the presence of ZYMV by indirect ELISA tests. After inoculation in January three accessions (BGH 1934, BGH-1937 and BGH-1943) were immune to ZYMV. Symptoms appeared in the susceptible accessions 10 to 15 days after the first inoculation whereas no symptoms were observed in the resistant and tolerant accessions until the end of the evaluation period and ELISA tests for virus concentration were negative. The accessions BGH-1934, BGH-1937, and BGH- 1943 can be used in breeding programs to incorporate resistance against ZYMV in commercial cultivars.
\end{abstract}

Keywords: Cucurbit moschata, resistance.

Palavras-chave: Cucurbita moschata, ZYMV, resistência.

(Recebido para publicação em 05 de janeiro de 2004 e aceioto em 21 de dezembro de 2004)

$\mathrm{D}^{\mathrm{i}}$ iversos fatores bióticos reduzem a produção das cucurbitáceas; dentre estes, as viroses podem causar severos prejuízos. O Zucchini yelow mosaic virus (ZYMV) é considerado um dos vírus mais importantes no cultivo de cucurbitáceas em diversos países (LISA; LECOQ, 1984; PROVVIDENTI et al., 1984; NAMETH et al., 1985; LECOQ et al., 1991). Desde a sua primeira ocorrência na Itália (1973) e posteriormente na França (1979), o vírus já foi observado em 50 países em plantações de cultivo intensivo de cucurbitáceas (DESBIEZ; LECOQ, 1997). Na California o ZYMV foi responsável por reduções de 40 a $50 \%$ na produção de frutos de melão, numa área de 7.500 ha plantada na primavera de 1984 (NAMETH et al., 1985). Na primavera de 1990, o ZYMV causou perda estimada em 22 milhões de dólares nessa mesma área cultivada com melão (PERRING et al., 1992). No Brasil, embora a ocorrência do vírus já tenha sido relatada em cucurbitáceas, não existem dados quantitativos sobre danos causados pelo ZYMV.

Dentre os diversos métodos de controle de viroses, a incorporação de genes de resistência pode minimizar perdas na produção, além de reduzir riscos de contaminação por agrotóxicos, tanto por parte dos agricultores quanto pelos consumidores. A busca por esses genes pode ser feita mediante a avaliação de acessos de Bancos de Germoplasma de $\mathrm{Cu}$ curbitáceas, incluindo as espécies cultivadas, principalmente os acessos existentes na agricultura tradicional do Nordeste brasileiro.

A resistência natural de plantas a vírus pode ser classificada em diferentes níveis (HULL; DAVIES,1992): (i) imunidade, no qual o vírus não se multipli- ca; (ii) infecção subliminal, na qual a replicação do vírus limita-se às células inicialmente infectadas, não ocorrendo movimento célula-a-célula; (iii) reação de hipersensibilidade, onde a infecção viral fica restrita às células vizinhas ao sítio primário de infecção, normalmente causando necrose, e (iv) tolerância, caracterizada por infecção sistêmica pouco severa ou mesmo assintomática, apesar da replicação viral não ser afetada.

Em pepino, foram identificadas duas fontes de resistência natural ao ZYMV, condicionado por alelos recessivos que ocorrem no mesmo locus (TMG-1 e Dina-1) (ULLAH; GRUMET, 2002). No entanto, os alelos diferem quanto à expressão do fenótipo. O híbrido Dina apresenta clorose de nervuras limitada à primeira folha, com as demais livres de sintomas, enquanto a linhagem TMG-1 expressa sintomas sistêmicos. 
O padrão de clorose de nervuras em Dina-1 sugere a inibição do movimento à longa distância, provavelmente um bloqueio da saída do vírus do tecido vascular. Situações similares foram descritas com o Barley yellow mosaic virus (BYMV) (DING et al., 1999).

Fontes de resistência ao ZYMV já foram identificadas em coleções de germoplasma de cucurbitáceas em Fortaleza, Ceará (OLIVEIRA et al., 2002). A espécie silvestre C. ecuadorensis Cutler e Whitaker contém gene de resistência para esse potyvírus e tem sido utilizada em cruzamentos interespecíficos em programas de melhoramento (DESBIEZ; LECOQ, 1997).

O presente estudo teve como objetivo avaliar os acessos de abóbora pertencentes aos Banco de Germoplasma de Hortaliças da UFV e Banco Ativo de Cucurbitáceas da Embrapa Semi-Árido visando identificar fontes de resistência ao ZYMV.

\section{MATERIAL E MÉTODOS}

Os experimentos foram conduzidos no Laboratório de Virologia Vegetal e no setor de olericultura da UFV, nos meses de janeiro e julho de 2001.

O isolado de ZYMV foi obtido de plantas de abóbora, coletado no município de Tocantins (MG), por Richards (1999).

Para a avaliação da resistência ao ZYMV foram instalados dois ensaios, um na época quente (janeiro de 2001) e o outro na época fria (julho de 2001). Em cada ensaio, foram avaliados 100 acessos de abóbora sendo 37 pertencentes ao BGH-UFV, 61 ao BAG da Embrapa Semi-Árido e dois híbridos cedidos pela empresa de sementes Sakata Seed Sudamérica Ltda. Os ensaios foram instalados no campus da UFV, sob telado, no delineamento experimental em blocos inteiramente ao acaso, com quatro repetições, sendo uma repetição considerada como um vaso com uma planta.

O ZYMV foi transmitido via extrato vegetal tamponado utilizando como inóculo $0,5 \mathrm{~g}$ de folhas de $C$. pepo 'Caserta' maceradas em almofariz, a frio, em tampão fosfato $0,05 \mathrm{M}, \mathrm{pH} 7,2$ contendo sulfito de sódio 0,01 M. A pri-

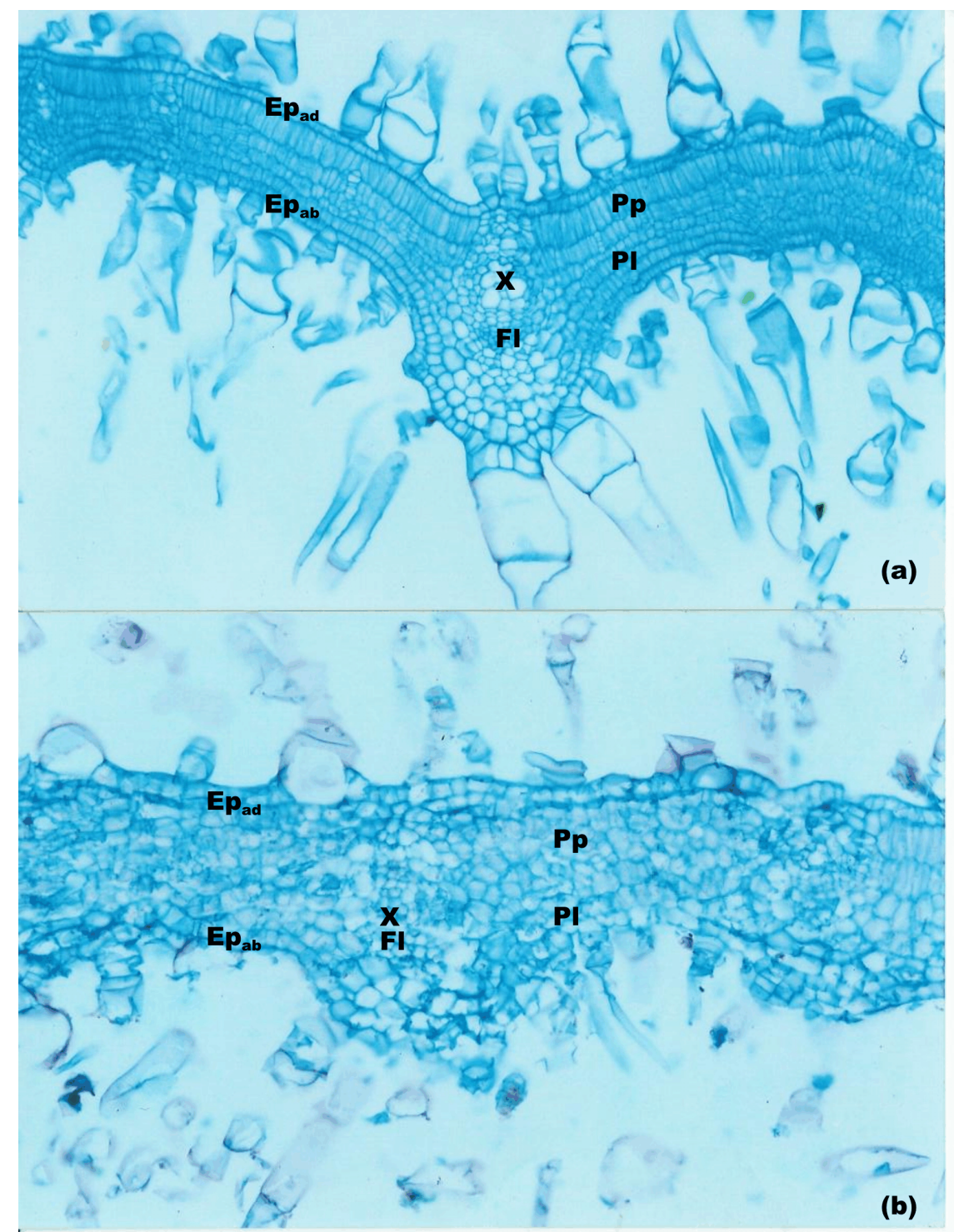

Figura 1. (a) Anatomia da folha sadia de abóbora do acesso BGH-1943. (b) Anatomia da folha de abóbora do acesso BAG-186, quando infectada pelo ZYMV. $\mathrm{E}_{\text {pad }}$ (epiderme adaxial) $\mathrm{E}_{\text {pab }}$ (epiderme abaxial), $\mathrm{P}_{\mathrm{p}}$ (parênquima paliçádico) $\mathrm{P}_{1}$ (parênquima lacunoso), $\mathrm{X}$ (xilema), $\mathrm{F}_{1}$ (floema).

meira inoculação foi feita nas folhas cotiledonares, utilizando-se óxido de alumínio (Carborundum) como abrasivo. Uma segunda inoculação foi feita dois dias após a primeira. A reação da planta ao ZYMV nas populações de abóbora foi classificada de acordo com a presença ou ausência dos sintomas e replicação viral nas classes Imune (sintomas e replicação viral ausentes), Resistente (sintomas ausentes e replicação viral reduzida), Tolerante (sintomas ausentes e replicação viral normal) ou Suscetível (sintomas presentes como clorose, mosaico com embolhamento e/ ou deformação do limbo foliar, epinastia ,enação, redução do crescimento e replicação viral normal).

O teste de ELISA indireto (CLARK et al., 1986) foi realizado a partir de extratos de folhas sadias de C. pepo 'Caserta' (controle negativo) e de folhas infectadas com ZYMV de $C$. pepo 'Caserta' (controle positivo) bem como as folhas novas dos acessos de abóbora que não expressaram sintomas 30 dias após inoculação com ZYMV, somente na época quente. As amostras foram maceradas em sacos plásticos transparentes na presença de tampão de extração. Pesou-se aproximadamente $0,5 \mathrm{~g}$ de folhas jovens e adicionaram-se 2,5 
Tabela 1. Estimativa da concentração do ZYMV nas folhas jovens (folhas do ápice da rama principal) dos acessos de abóbora que não expressaram sintomas aos trinta dias após a primeira inoculação, em casa de vegetação, na época quente (Janeiro). Viçosa, UFV, 2001

\begin{tabular}{|c|c|c|c|}
\hline Código de acesso & $\begin{array}{l}\text { Concentração do ZYMV na } \\
\text { folha de abóbora }\end{array}$ & $\begin{array}{l}\text { Amplitude dos valores da } \\
\text { concentração do ZYMV na } \\
\text { folha de abóbora }\end{array}$ & Reação da planta ao ZYMV \\
\hline Controle positivo & $1,146 \mathrm{~A}$ & $0,821-1,740$ & \\
\hline Controle negativo & $0,412 \mathrm{C}$ & $0,309-0,488$ & \\
\hline BGH-1934 & $0,512 \mathrm{C}$ & $0,408-0,533$ & Imune \\
\hline BGH-1937 & $0,575 \mathrm{C}$ & $0,314-0,578$ & Imune \\
\hline BGH-1943 & $0,572 \mathrm{C}$ & $0,408-0,580$ & Imune \\
\hline Híbrido HAF-2656 & $0,739 \mathrm{~B}$ & $0,678-0,850$ & Resistente \\
\hline BAG-006 & $0,752 \mathrm{~B}$ & $0,650-0,830$ & Resistente \\
\hline BAG-30 & $0,758 \mathrm{~B}$ & $0,666-0,846$ & Resistente \\
\hline BAG-34 & $0,718 \mathrm{~B}$ & $0,633-0,891$ & Resistente \\
\hline BAG-35 & $0,777 \mathrm{~B}$ & $0,615-0,979$ & Resistente \\
\hline BAG-52 & $0,695 \mathrm{~B}$ & $0,547-0,860$ & Resistente \\
\hline BAG-53 & $0,745 \mathrm{~B}$ & $0,555-0,884$ & Resistente \\
\hline BAG-78 & $0,688 \mathrm{~B}$ & $0,600-0,800$ & Resistente \\
\hline BAG-86 & $0,731 \mathrm{~B}$ & $0,687-0,800$ & Resistente \\
\hline BAG-90 & $0,722 \mathrm{~B}$ & $0,633-0,891$ & Resistente \\
\hline BAG-93 & $0,709 \mathrm{~B}$ & $0,602-0,801$ & Resistente \\
\hline BAG-94 & $0,713 \mathrm{~B}$ & $0,680-0,770$ & Resistente \\
\hline BAG-102 & $0,682 \mathrm{~B}$ & $0,600-0,800$ & Resistente \\
\hline BAG-104 & $0,667 \mathrm{~B}$ & $0,638-0,700$ & Resistente \\
\hline BAG-105 & $0,628 \mathrm{~B}$ & $0,540-0,698$ & Resistente \\
\hline BAG-106 & $0,722 \mathrm{~B}$ & $0,584-0,886$ & Resistente \\
\hline BAG-107 & $0,711 \mathrm{~B}$ & $0,680-0,770$ & Resistente \\
\hline BAG-117 & 0,653 B & $0,468-0,855$ & Resistente \\
\hline BAG-176 & $0,759 \mathrm{~B}$ & $0,666-0,846$ & Resistente \\
\hline BAG-179 & $0,741 \mathrm{~B}$ & $0,555-0,850$ & Resistente \\
\hline BAG-188 & $0,739 \mathrm{~B}$ & $0,432-0,970$ & Resistente \\
\hline BGH-4517 & $0,783 \mathrm{~B}$ & $0,675-0,860$ & Resistente \\
\hline BGH-5210 & $0,785 \mathrm{~B}$ & $0,675-0,860$ & Resistente \\
\hline BGH-5257 & $0,720 \mathrm{~B}$ & $0,633-0,891$ & Resistente \\
\hline BGH-5602 & $0,698 \mathrm{~B}$ & $0,646-0,759$ & Resistente \\
\hline BGH-6586 & $0,765 \mathrm{~B}$ & $0,648-0,838$ & Resistente \\
\hline Híbrido HAF-2657 & $0,880 \mathrm{~A}$ & $0,864-0,900$ & Tolerante \\
\hline BAG-001 & $0,821 \mathrm{~A}$ & $0,780-0,891$ & Tolerante \\
\hline BAG-003 & $0,800 \mathrm{~A}$ & $0,633-0,870$ & Tolerante \\
\hline BAG-014 & $0,871 \mathrm{~A}$ & $0,843-0,927$ & Tolerante \\
\hline BAG-025 & $0,979 \mathrm{~A}$ & $0,820-1,413$ & Tolerante \\
\hline BAG-026 & $0,809 \mathrm{~A}$ & $0,650-0,979$ & Tolerante \\
\hline BAG-28 & $0,931 \mathrm{~A}$ & $0,785-1,100$ & Tolerante \\
\hline BAG-042 & $0,979 \mathrm{~A}$ & $0,820-1,413$ & Tolerante \\
\hline BAG-048 & $0,833 \mathrm{~A}$ & $0,664-0,938$ & Tolerante \\
\hline BAG-062 & $1,079 \mathrm{~A}$ & $0,790-1,102$ & Tolerante \\
\hline BAG-066 & $0,932 \mathrm{~A}$ & $0,806-1,184$ & Tolerante \\
\hline BAG-067 & $0,907 \mathrm{~A}$ & $0,848-1,070$ & Tolerante \\
\hline BAG-068 & $1,084 \mathrm{~A}$ & $0,832-1,200$ & Tolerante \\
\hline BAG-069 & $1,116 \mathrm{~A}$ & $0,825-1,157$ & Tolerante \\
\hline BAG-072 & $0,880 \mathrm{~A}$ & $0,845-0,938$ & Tolerante \\
\hline BAG-077 & $0,918 \mathrm{~A}$ & $0,806-1,061$ & Tolerante \\
\hline BAG-080 & $0,818 \mathrm{~A}$ & $0,690-0,926$ & Tolerante \\
\hline BAG-083 & $0,854 \mathrm{~A}$ & $0,605-0,970$ & Tolerante \\
\hline
\end{tabular}

${ }^{1}$ Médias seguidas de mesma letra, em cada coluna, pertencem a um mesmo grupo, de acordo com o teste de Scott-Knott, a 5\% de probabilidade. 
Tabela 1. (Continuação)

\begin{tabular}{|c|c|c|c|}
\hline Código de acesso & $\begin{array}{l}\text { Concentração do ZYMV na } \\
\text { folha de abóbora }\end{array}$ & $\begin{array}{l}\text { Amplitude dos valores da } \\
\text { concentração do ZYMV na } \\
\text { folha de abóbora }\end{array}$ & Reação da planta ao ZYMV \\
\hline BAG-089 & $0,859 \mathrm{~A}$ & $0,826-0,910$ & Tolerante \\
\hline BAG-092 & $0,985 \mathrm{~A}$ & $0,662-1,142$ & Tolerante \\
\hline BAG-096 & $0,861 \mathrm{~A}$ & $0,790-0,948$ & Tolerante \\
\hline BAG-110 & $1,042 \mathrm{~A}$ & $0,826-1,125$ & Tolerante \\
\hline BAG-183 & $0,853 \mathrm{~A}$ & $0,605-0,970$ & Tolerante \\
\hline BAG-187 & $0,942 \mathrm{~A}$ & $0,800-1,140$ & Tolerante \\
\hline BAG-190 & $0,953 \mathrm{~A}$ & $0,835-1,150$ & Tolerante \\
\hline BAG-195 & $0,998 \mathrm{~A}$ & $0,838-1,240$ & Tolerante \\
\hline BAG-197 & $0,959 \mathrm{~A}$ & $0,797-1,200$ & Tolerante \\
\hline BAG-205 & $0,823 \mathrm{~A}$ & $0,677-1,031$ & Tolerante \\
\hline BGH-469 & $0,822 \mathrm{~A}$ & $0,721-0,863$ & Tolerante \\
\hline BGH-586 & $0,817 \mathrm{~A}$ & $0,794-0,902$ & Tolerante \\
\hline BGH-890 & $0,801 \mathrm{~A}$ & $0,700-0,870$ & Tolerante \\
\hline BGH-985 & $0,982 \mathrm{~A}$ & $0,806-1,053$ & Tolerante \\
\hline BGH-1961 & $0,819 \mathrm{~A}$ & $0,783-0,926$ & Tolerante \\
\hline BGH-3328 & $0,800 \mathrm{~A}$ & $0,700-1,055$ & Tolerante \\
\hline BGH-3333 & $1,146 \mathrm{~A}$ & $0,821-1,230$ & Tolerante \\
\hline BGH-3334 & $0,834 \mathrm{~A}$ & $0,780-0,872$ & Tolerante \\
\hline BGH-4281 & $0,837 \mathrm{~A}$ & $0,730-0,895$ & Tolerante \\
\hline BGH-4453 & $0,952 \mathrm{~A}$ & $0,810-1,320$ & Tolerante \\
\hline BGH-4516 & $0,865 \mathrm{~A}$ & $0,790-0,948$ & Tolerante \\
\hline BGH-4607 & $0,927 \mathrm{~A}$ & $0,780-1,213$ & Tolerante \\
\hline BGH-5226 & $0,996 \mathrm{~A}$ & $0,821-1,340$ & Tolerante \\
\hline BGH-5228 & $0,840 \mathrm{~A}$ & $0,720-0,925$ & Tolerante \\
\hline BGH-5255 & $0,978 \mathrm{~A}$ & $0,806-1,260$ & Tolerante \\
\hline BGH-5429 & $0,931 \mathrm{~A}$ & $0,785-1,100$ & Tolerante \\
\hline BGH-6352 & $1,012 \mathrm{~A}$ & $0,806-1,410$ & Tolerante \\
\hline BGH-6743 & $0,835 \mathrm{~A}$ & $0,706-0,970$ & Tolerante \\
\hline BGH-6752 & $0,863 \mathrm{~A}$ & $0,840-0,910$ & Tolerante \\
\hline BGH-6753 & $0,981 \mathrm{~A}$ & $0,806-1,260$ & Tolerante \\
\hline
\end{tabular}

${ }^{1}$ Médias seguidas de mesma letra, em cada coluna, pertencem a um mesmo grupo, de acordo com o teste de Scott-Knott, a 5\% de probabilidade.

ml de tampão (diluição 1:5). Em seguida, adicionaram-se $100 \mu \mathrm{l}$ de extrato nas respectivas cavidades da placa. Foram realizadas duas repetições para cada amostra. A incubação foi a $37^{\circ} \mathrm{C}$, por aproximadamente uma hora. Em seguida as placas foram lavadas três vezes, durante cinco minutos em cada lavagem, em tampão PBS-T (pH 7,4 com 0,1\% de Tween 20). Posteriormente, o antisoro previamente diluído em tampão PEP (1:10.000), foi adicionado às placas (100 $\mu \mathrm{l} /$ cavidade), seguindo-se incubação por uma hora a $37^{\circ} \mathrm{C}$. Após um ciclo de lavagem, o anticorpo conjugado à enzima fosfatase alcalina e previamente diluído em tampão PEP (1:2.000) foi adicionado às placas e incubado por três horas a $37^{\circ} \mathrm{C}$. As placas foram novamente lavadas, conforme descrito anteriormente e em seguida adicionouse o substrato p-nitrofenilfosfato, na concentração $0,5 \mathrm{ml}$. O substrato foi incubado por 5 a $15 \mathrm{~min}$, no escuro, à temperatura ambiente. Após a reação enzimática, a intensidade de coloração foi medida em leitora de Elisa, no comprimento de onda de $405 \mathrm{~nm}$.

A análise estatística foi realizada no programa GENES (CRUZ, 1997), realizando-se a análise de variância apenas para a variável concentração viral. O teste de Scott-Knott (1974), ao nível de significância de 5\% de probabilidade foi utilizado para estabelecer diferenças de grupos de médias entre os 77 acessos de abóbora que não expressaram sintomas até 30 dias após inoculação com o ZYMV, somente na época quente.

\section{RESULTADOS E DISCUSSÃO}

Dos 100 acessos inoculados com o ZYMV, no primeiro ensaio, os acessos BAG-19; BAG-27; BAG-38; BAG-40; BAG-54; BAG-61; BAG-65; BAG-73; BAG-101; BAG 120; BAG-151; BAG181; BAG-185; BAG-186; BAG-189; BAG-900; BGH-4459; BGH-4524; BGH-5233; BGH-5246; BGH-5431; BGH-5601 e BGH-6585 foram considerados suscetíveis por expressarem sintomas visíveis. Nos 77 acessos sem sintomas visuais, submetidos à avaliação da concentração viral, verificou-se diferença significativa entre as médias ao nível de $1 \%$ de probabilidade pelo Teste F. 
O ZYMV causou sintomas severos, com grande variabilidade de expressão nas folhas, nos 100 acessos de abóbora, na época fria. $\mathrm{O}$ vírus provocou forte desorganização no arranjo e na forma das células epidérmicas e do parênquima paliçádico, além de induzir hiperplasia nas células (Figura 1).

$\mathrm{Na}$ época fria, todos os acessos inoculados com ZYMV expressaram sintomas. Não foi realizado o teste de ELISA para quantificar a concentração do ZYMV para estes acessos.

Em função da concentração viral foram obtidos os seguintes resultados, na época quente: 3 acessos foram considerados imunes, 26 resistentes e 48 tolerantes (Tabela 1); representando, portanto, fontes promissoras para serem empregadas em programas futuros de melhoramento genético visando à incorporação de genes de resistência a este vírus em espécies de Cucurbita. Brown et al. (2003) confirmaram o mecanismo de resistência de Cucurbita moschata ao ZYMV, conferido por um fator monogênico dominante designado Zym. Provvidenti (1986) identificou fontes de resistência às estirpes ZYMV-FL e ZYMV-CT em dois acessos de $C$. colocynthis e relata que essa resistência era melhor expressada em temperaturas elevadas, o que coincide com os resultados do presente trabalho. Não obstante terem sido encontrado muitos acessos tolerantes ao ZYMV, estes não são considerados fontes promissoras para o melhoramento, por apresentarem infec- ção latente e desta forma funcionarem como fonte primária de disseminação do vírus. $\mathrm{Na}$ época fria (julho) todos os acessos expressaram sintomas quando inoculados com o ZYMV. No entanto, os acessos BGH-1934, BGH-1937 e BGH-1943, considerados imunes na época quente, expressaram sintomas atenuados.

\section{AGRADECIMENTOS}

A primeira autora agradece ao Conselho Nacional de Desenvolvimento Científico e Tecnológico pela concessão de bolsa de doutorado.

\section{LITERATURA CITADA}

BROWN, R.N.; HERRERA-BOLANOS, A; MYERS, J.R.; JAHN,M.M. Inheritance of resistance to four cucurbit viruses in Cucurbita moschata. Euphytica, v.129, p.253-258, 2003.

CLARK, M.F.; LISTER, R.M.; BAR-JOSEPH, M. ELISA techniques. Methods in Enzymology, v.118, p.742-766, 1986.

CRUZ, C.D. Programa Genes: aplicativo computacional em genética e estatística. Viçosa:UFV, 1997. 442 p.

DESBIEZ, C.; LECOQ, H. Zucchini yellow mosaic virus. Plant Pathology, v.46, n.6, p.809829, 1997.

DING, X.S.; FLASINSKI, S.; NELSON, R.S. Infection of barley by Brome mosaic virus is restricted predominantly to cells in and associated with veins through temperature dependent mechanism. Molecular Plant-Microbe Interactions, v.12, n.7, p.615-623, 1999.

HULL, R.; DAVIES, J.W. Approaches to non conventional control of plant virus diseases. Critical Reviews in Plant Sciences, v.11, p.17-33, 1992.
LECOQ, H.O.; LEMAIRE, J.M.; WIPFSCHELBEL, C. Control of Zucchini yellow mosaic virus in squash by cross protection. Plant Disease, v.75, p.208-211, 1991.

LISA, V.; LECOQ, H. Zucchini yellow mosaic virus. CMI/AAB. Descriptions of Plant Viruses, n.282, p.4, 1984.

NAMETH, S.T.; DODDS, J.A.; PAULUS, A.O.; KISHBA, A. Zucchini yellow mosaic virus associated with severe diseases of melon and watermelon in Southeastern California desert valleys. Plant Disease, v.69, n.9, p.785-788, 1985. OLIVEIRA, V.B.; QUEIROZ, M.A.; LIMA, J.A.A. Fontes de resistência em melancia aos principais isolados de cucurbitáceas no Nordeste brasileiro. Horticultura Brasileira, Brasília, v.20, n.4, p.589-592, 2002.

PERRING, T.M.; FARRAR, C.A.; MAYBERRY, K.; BLUA, M.J. Research reveals pattern of cucurbit virus spread. California Agriculture, v.46, p.35-40, 1992.

PROVVIDENTI, R.; GONSALVES, D.; HUMAYDAN, H.S. Occurrence of Zucchini yellow mosaic virus in cucurbits from Connecticut, New York, Florida, and California. Plant Disease, v.68, p.443-446, 1984.

PROVVIDENT, R. Reaction of accessions of Citrullus colocynthis from Nigeria to zucchini yellow mosaic virus and other cucurbit viruses. Cucurbit Genetic Cooperative Report, n.9, p.82$83,1986$.

RICHARDS, R.S. Identificação, caracterização biológica e obtenção de sondas de cDNA para virus de cucurbitáceas no Estado de Minas Gerais. Viçosa-MG: UFV, 1999. 87 f. (Tese mestrado) - UFV, Viçosa.

SCOTT-KNOTT, A.J.; KNOTT, M. Cluster analysis method for grouping means in the analysis of variance. Biometrics, v.30, n.1, p.507-512, 1974.

ULLAH, Z.; GRUMET, R. Localization of Zucchini yellow mosaic virus to the veinal regions and role of viral coat protein in veinal chlorosis conditioned by the zym potyvirus resistance locus in cucumber. Physiological and Molecular Plant Pathology, v.60, n.2, p.79-89, 2002. 